\title{
Genetic influence alters the brain synchronism in perception and timing
}

\author{
Victor Marinho ${ }^{1,2,3^{*}}$, Thomaz Oliveira ${ }^{1,2}$, Juliete Bandeira', Giovanny R. Pinto ${ }^{2,3}$, Anderson Gomes², Valéria Lima², \\ Francisco Magalhães ${ }^{1,3}$, Kaline Rocha ${ }^{1,3}$, Carla Ayres ${ }^{1}$, Valécia Carvalho ${ }^{1,3}$, Bruna Velasques ${ }^{4}$, Pedro Ribeiro ${ }^{4}$, \\ Marco Orsini ${ }^{5}$, Victor Hugo Bastos ${ }^{6}$, Daya Gupta ${ }^{7}$ and Silmar Teixeira ${ }^{1,3}$
}

\begin{abstract}
Background: Studies at the molecular level aim to integrate genetic and neurobiological data to provide an increasingly detailed understanding of phenotypes related to the ability in time perception.

Main Text: This study suggests that the polymorphisms genetic SLC6A4 5-HTTLPR, 5HTR2A T102C, DRD2/ANKK1Taq1A, SLC6A3 3'-UTR VNTR, COMT Val158Met, CLOCK genes and GABRB2 A/C as modification factor at neurochemical levels associated with several neurofunctional aspects, modifying the circadian rhythm and built-in cognitive functions in the timing. We conducted a literature review with 102 studies that met inclusion criteria to synthesize findings on genetic polymorphisms and their influence on the timing.

Conclusion: The findings suggest an association of genetic polymorphisms on behavioral aspects related in timing. However, order to confirm the paradigm of association in the timing as a function of the molecular level, still need to be addressed future research.
\end{abstract}

Keywords: Time perception, Genetic polymorphisms, Serotonin, Dopamine, Circadian rhythm, GABA

\section{Background}

The interindividual differences in the time perception are evident in daily actions and their neurobiological aspects (i.e. walking, talking, reward tasks, executive functions, and cognition), with neurotransmitters acting in synchronization of the Central Nervous System (CNS). Neurotransmitters actions help to synchronize stimuli $[1,2]$, and trigger responses on time scales that range from the milliseconds (motor coordination), seconds to minutes (conscious time perception) and hours of the day (circadian rhythms) [3, 4]. It has been known that the genetic makeup enables the coding of different environmental stimuli, modulated through the action of the serotonergic, dopaminergic, GABAergic neurotransmission as well as circadian oscillations [5].

\footnotetext{
* Correspondence: victormarinhophb@hotmail.com

${ }^{1}$ Neuro-innovation Technology \& Brain Mapping Laboratory, Federal University of Piauí, Av. São Sebastião n² 2819 - Nossa Sra. de Fátima -, Parnaíba, PI CEP 64202-020, Brazil

${ }^{2}$ Genetics and Molecular Biology Laboratory, Federal University of Piauí, Parnaíba, Brazil

Full list of author information is available at the end of the article
}

The hypothesis that the genetic polymorphisms in the expression of neurotransmitter systems and in circadian rhythm influences the perceptual capacity [6], promoted an increase in the number of genetic research to understand the molecular underpinnings of the temporal processing. To evaluate the genetic factors in temporal processing, Balci et al. [7] and Meck et al. [8] analyzed the effects of 5HTR2A, SLC6A4, SLC6A3 and DRD2 expression on peak interval (PI) or non-reward procedures in rats. Results showed that rats genetically knockout for 5HTR2A, SLC6A4, SLC6A3, and DRD2 have less precision in the performance of PI activities when compared to control rats. This supports the importance of the role of several gene products in the phenotypic behavior associated with processing time intervals.

Genotypic investigations regarding brain function associated with timing are passive to determination of endophenotypes [9]. The literature seeks to trace a genetic profile of association with psychometric functions and behavioral performances, for example, fear conditioning, timing tasks by means of visual, tactile or auditory stimuli in humans or other species (Table 1) [10-

(C) The Author(s). 2018 Open Access This article is distributed under the terms of the Creative Commons Attribution 4.0 International License (http://creativecommons.org/licenses/by/4.0/), which permits unrestricted use, distribution, and 
Table 1 Summary of genetic studies investigating the impact of time perception

\begin{tabular}{|c|c|c|c|c|}
\hline Genotyping & Protocol & Stimulus & Duration & Results \\
\hline SLC6A3 5-HTTLPR & $\begin{array}{l}\text { Group: } 273 \text { young healthy. } \\
\text { Cognitive tasks: (memory and } \\
\text { Face Identity Perception tasks). }\end{array}$ & $\begin{array}{l}\text { Visual } \\
\text { Face } \\
\text { images }\end{array}$ & $\begin{array}{l}\text { Seconds range, varied for } \\
\text { each participant. }\end{array}$ & $\begin{array}{l}\text { There was neither an association between the } 5 H T T L P R \\
\text { genotype and cognitive tasks, but there might be a } \\
\text { tendency for better performance of SL as compared } \\
\text { with SS carriers for fEP [24]. }\end{array}$ \\
\hline $\begin{array}{l}\text { SLC6A4 5-HTTLPR, 5HT2A T102C, DRD2/ } \\
\text { ANKK1-Taq1A, SLC6A3 3'-UTR VNTR, } \\
\text { COMT Val158Met, MAOA VNTR, and } \\
\text { CLOCK genes. }\end{array}$ & $\begin{array}{l}\text { Group: } 647 \text { healthy individuals, } \\
\text { Questionnaire. Cognitive test. } \\
\text { Production and Discrimation } \\
\text { tasks. }\end{array}$ & $\begin{array}{l}\text { Visual } \\
\text { Auditory }\end{array}$ & $1 \mathrm{~s}, 3 \mathrm{~s}, 6 \mathrm{~s}, 12 \mathrm{~s}, 15 \mathrm{~s}$ & $\begin{array}{l}\text { Stability of an individual's temporal accuracy and } \\
\text { precision across in supra-second intervals (ranging } \\
\text { from } 3 \mathrm{~s} \text { to } 15 \mathrm{~s} \text { ) in the cognitive tasks and time per- } \\
\text { ception tasks. Female participants are more likely to } \\
\text { underestimate time production task when an explicit } \\
\text { counting strategy is not employed [6]. }\end{array}$ \\
\hline COMT Val158Met, 5HTR2A T102C. & $\begin{array}{l}\text { Group: } 90 \text { healthy Japanese. } \\
\text { Cognitive tasks and fMRI study. }\end{array}$ & Visual & $2 \mathrm{~s}, 3 \mathrm{~s}$ & $\begin{array}{l}\text { Results demonstrate that the COMT genotypes are } \\
\text { related to recognition accuracy, whereas the 5HTR2A } \\
\text { genotypes are associated with RTs for recognition. In } \\
\text { addition, strong connectivity in the cingulo-frontal net- } \\
\text { works is closely linked to a better working memory } \\
\text { performance, regardless of the genotypes [98]. }\end{array}$ \\
\hline
\end{tabular}

COMT Val158Met, SLC6A3 3'UTR VNTR and DRD4 exon 3 VNTR.

DRD2/ANKK1-Taq1A.

DRD2/ANKK1-Taq1A and COMT Val158Met.

COMT Val158Met, SLC6A3 3'-UTR VNTR.

SLCGA3 +/+ rats

SLCGA3 - - rats

SLC6A3 +/- rats

DRD2/ANKK1-Taq1A and COMT Val158Met.

SLC6A3 +/+ rats

SLC6A3 - - rats

SLC6A3 +/- rats

SLC6A4 5-HTTLPR, 5HT2A T102C, DRD2/ ANKK1-Taq1A, SLC6A3 3'-UTR VNTR and COMT Val158Met.

DRD2/ANKK1-Taq1A
Group: 52 healthy Estonians. Visual 23 ms, 70 ms, 105 ms, Cognitive tasks and

Discrimination task. Temporal or color

Discrimination task and fMRI acquisition

Group: 41 healthy individuals. Time perception tasks. Fixedintervals tasks. 64-channel EEG study. Continuous performance test.

Group: DAT-mutant rat. Peak interval task. Administration:

Methamphetamine

hydrochloride.

Group: 65 healthy individuals. Temporal discrimination task and motor tempo task.

$735 \mathrm{~ms}$, $2,6 \mathrm{~s}$

Visual $10 \mathrm{~s}, 17 \mathrm{~s}$.

Visual $900 \mathrm{~ms}$

Visual $\quad 15 \mathrm{~s}, 20 \mathrm{~s}, 45 \mathrm{~s}, 140 \mathrm{~s}$, $200 \mathrm{~s}$

Visual $\quad 500 \mathrm{~ms}, 2 \mathrm{~s}$
Group: 25 healthy individuals. Visual

$350 \mathrm{~ms}, 400 \mathrm{~ms}, 450 \mathrm{~ms}$, $550 \mathrm{~ms}, 600 \mathrm{~ms}, 650 \mathrm{~ms}$; $1,4 \mathrm{~s}, 1,8 \mathrm{~s}, 2 \mathrm{~s}, 2,2 \mathrm{~s}, 2,4$

$450 \mathrm{~ms}, 600 \mathrm{~ms}, 750 \mathrm{~ms}$

Group: KD rat and WT rat. Peak Visual interval task and administration of the

, 0 s, 40s, 60s, 80s, $100 s$, $120 \mathrm{~s}$.

Raclopride.

Group: 44 healthy individuals. Discrimination task.

Visual Combinations of supra Auditory seconds.

Group: Transgenic rat C57BL/6- No Fixed-interval: 24 s. CB. Peak interval tasks.
SLC6A3 variability no showed difference in study. COMT Val158Met and DRD4 exon 3 VNTR differ in their effects on attentional functions as explicated in long-SOA metacontrast [20].

A1 carriers of the Taq1A polymorphism exhibited worse performance on temporal task. However, greater activation in the striatum and right dorsolateral prefrontal cortex, as well as reduced volume in the cerebellar [22].

DRD2/ANKK1-Taq1A in the striatum and COMT Val158Met, affecting the breakdown of dopamine in the prefrontal cortex - to interval timing and reward magnitude modulation of decision thresholds [7].

Effects of SLC6A3 and COMT on the occipito-temporal activity in CNV. In addition, there was a trend towards an interaction between the two polymorphisms [19].

Complete loss of temporal control and altered sensitivity to drugs. Lower threshold for initiating responding in the timing task [8].

DRD2/ANKK1-Taq1A (A1+ allele) was associated with variability for the 500 ms duration only, whereas the COMT Val158Met ( Val/Nal) was associated with variability for the $2000 \mathrm{~ms}$ duration only. Additionally, the DRD2/ANKK1-Taq1A was associated with slower preferred motor time [21].

DAT KD rats responded at higher levels in peak trials than WT rats in all conditions, but particularly during the fixed-interval 30 peak trials [1].

No differences between time representation and dopamine-genes. However, show association between serotinine-related genes and parameters derived from psychometric functions PSE [13].

Overexpression of D2 receptors in the striatum caused a reduction in operant response rate, a broadening of the distribution of operant responses in time and an increase in the latency of the peak in response rate, consistent with an impairment in timing accuracy. The progressive ratio operant task confirmed that D2 overexpressing rats exhibited reduced operant motivation [23].
12]. In principle, human cognitive performance is highly variable and under strong genetic control. Moreover, qualitative or quantitative genetic changes promote underestimation or overestimation of time according to the Scalar Expectancy Theory (SET) [5, 13, 14]. This is accounted by the interference in the number of oscillations captured per time unit from the internal clock $[15,16]$, and judgments of time intervals may result from changes in the pulse flow from an internal pacemaker in the presence of an event [17]. Consequently, genetic polymorphisms increase or decrease the speed of the internal clock, modulating the 
neurotransmission of the pulses and reactions to stimuli that determine the synchronism in motor and cognitive activities [11, 13, 18].

Therefore, the individual variability in the coding of the time intervals resulting from single nucleotide polymorphisms (SNPs) and numbers of tandem repeat variations (VNTRs) modifies timing process [19, 20]. In summary, studies suggest that the SLC6A4 5-HTTLPR, 5HTR2A T102C, DRD2/ANKK1-Taq1A, SLC6A3 3'-UTR VNTR, COMT Val158Met, CLOCK genes and GABRB2 A/C (rs6556547) expression in the cortical and subcortical areas influence the time judgment. Thus, it becomes relevant for neurogenetics to elucidate endophenotypes associated with the perception of the sub-second and supra-second intervals $[6,11,13,18,21]$.

Finally, we presented a state-of-the-art for genetic polymorphisms and time perception, highlighting the main discoveries, and addressing further directions for clinically relevant neuroscience research. Although we have some papers not directly related to genetic influence on the time perception; these additional studies demonstrate behavioral phenotypes related to cognition and executive function, both have a key role in time intervals synchronization. These studies support neurochemical changes caused by differential gene expression, as well as a relationship with cognitive modulations embedded in ability to synchronize the time intervals.

\section{Genetic of the serotoninergic system on the neurobiological aspects inbuilt in timing}

Analyses of neural and genetic mechanisms have contributed to the understanding of how the time-trial process occurs [19]. Sysoeval, Tonevitsky and Wackermann [13] investigated differences in the neurobiological basis in perceiving stimuli through polymorphisms analysis (SLC6A4 5-HTTLPR, 5HTR2A T102C, DRD2/ ANKK1-Taq1A, SLC6A3 3'-UTR VNTR and COMT Val158Met) concomitantly with time discrimination tasks. Since the results do not reveal consistencies in data from the studies of genetic polymorphisms related to the dopaminergic system, it may be inferred that increased or decreased serotonin expression also influences the processing of time intervals. The results demonstrated that chemical modulations in the CNS in perceptive activities relates to serotonin concentration in the coding second to minutes duration intervals. Genetic polymorphisms in neurotransmission predispose participants to different behavioral phenotypes, and consequently we infer inappropriate recruitment, decrease or increase of neurotransmitters levels, which causes modulations of neural inputs in the timing circuits.

In particular, a biomarker of serotoninergic expression related to individual variability in cognition, the SLC6A4 gene located in 17q11.2, encode a transmembrane protein that transports serotonin from synaptic spaces. An In/Del polymorphism exists within the $5^{\prime}$ region flanking the regulatory region of the SLC6A4 gene, a highly polymorphic region (5-HTTLPR) associated with levels of transport and serotonin uptake. The genotypes related to SLC6A4 5-HTTLPR, the short allele (S) show decreased serotonin reabsorption compared to the long allele $(\mathrm{L})[25,26]$. The allelic differences are associated with a decrease in the availability of serotonin. Individuals carrying the short allele have increased extracellular serotonergic levels compared to those with two copies of the long allele [27]. Fallgatter et al. [10] confirmed that individuals with one or two copies of the SLC6A4 5-HTTLPR short allele have greater brain activity and less error in memory and timing stimulus activities. Therefore, Heinz et al. [28] reported that the healthy carriers of short alleles of the SLC6A4 5-HTTLPR have increased amygdaloid neuron activation and the connection of neural inputs between the amygdala and the ventromedial prefrontal cortex than homozygous individuals for the long allele. It has been shown that genetic variations that encode serotonin play a central role in social learning neurobiology, the system of emotions and decision making.

Additionally, neurochemistry influences working memory, which is a system of limited capacity that permeates almost all levels of cognition, ranging from perceptive awareness to intelligence [29]. Thus, cortical and subcortical signaling is influenced by the receptors differential expression of receptors in regions of the brain that are involved in perceptual processing and executive functions. Accordingly, Crisan et al. [30] investigated the effects of SLC6A4 5-HTTLPR polymorphism concomitant with neuroimaging tools, through tasks that measure decision-making on economic risks in healthy financial market volunteers. The results of genotyping in the 5-HTTLPR region in this retrospective study indicate that carriers of the short alleles, same in heterozygosity, exhibit better performance in financial activities and a lower percentage of economic losses compared to homozygotes for the long allele. The relationship of SLC6A4 5-HTTLPR polymorphism with variable serotonin expression has been associated with neuropsychiatric conditions [11], social anxiety disorder [31], aggressiveness [32], depression [33] and impulsivity [34], diseases that contribute to the deficit in the time perception. However, genetic studies associated with cognitive parameters are not only linked to SLC6A4 5-HTTLPR [35], but the studies by Burt and Mikolajewski [36] show that that subjects make less harmful decisions, besides an adjuvant action of variations in the $5 H T R 2 A$ gene on cognitive aspects.

The 5HTR2A gene located at 13q14-21 encodes the expression of postsynaptic type 2A (5-HT2A) serotonin 
receptors, which signal via diacylglycerol and triphosphate inositol during serotonergic stimulation. The $5 H T R 2 A$ gene influences the perceptual capacity of stimuli and executive functions [36], and are associated with impulsivity disorders in motor and cognitive planning tasks, likely from deficient connections as well as a decrease of serotonergic receptors in brain regions that perform these activities (i.e. prefrontal cortex and limbic system) [36, 37]. The 5HTR2A T102C polymorphism corresponds to a thymine $(\mathrm{T})$ shift by a cytosine $(\mathrm{C})$ at position 102 of the codon in the promoter region of the gene and determines changes in the amino acid coding that make up the $2 \mathrm{~A}$ receptors. Genotypes with $\mathrm{TT}$ alleles have higher expression of 5-HT2A than homozygous CC and heterozygous TC [38]. The genotypes studies at a molecular level in conjunction with pharmacological models suggests that the 5HTR2A T102C polymorphism modulates the timing activity of visual stimuli in work memory tasks [39]. The ability to influence the perception of visual stimuli is because 5-HT2A receptors are highly expressed in the visual cortex [40]. Thus, the alterations in the density of the occipital cortex due to genetic variations decrease the expression of 5-HT2A, which facilitate the appearance of deficiencies in time interpretation and in risk of neurological diseases [41, 42].

\section{Genetic aspects of the dopaminergic system in timing}

The control in the human ability to judge the time intervals originated of the external stimuli has as one of the bases, the dopaminergic system [11, 43]. Among the genes that influence dopaminergic neurotransmission, the DRD2 gene located in 11q23.2, encodes a G protein-coupled receptor in postsynaptic neurons, playing a key role in neurotransmission, besides influencing several behavioral phenotypes $[44,45]$. In particular, SNP DRD2/ANKK1-Taq1A triggers glutamate changes by lysine (Glu713Lys) in $A N K K 1$, altering the function of the DRD2 promoter region and expression of the D2-type receptors. In view of the foregoing, two alleles (A1 and A2) can be identified, the presence of one or two alleles A1 is associated with the reduction of 20 to $40 \%$ of the D2 receptor in areas of the striatum, region essential in the encoding of neural inputs in the timing $[13,46]$. The transient expression of D2 receptors have been demonstrated to cause a deficit in neural mechanisms in the indirect pathway activation of the prefrontal cortex, motor cortex, and premotor, consequently, thus impairs the acquisition of temporal control, and results in underestimation during timed-motor tasks [7].

Furthermore, molecular influence on dopaminergic neurotransmission in presynaptic terminals is mediated by $S L C 6 A 3$ gene located in $5 \mathrm{p} 15.3$, important to the chemical regulation between dopaminergic circuits and pathways related to cognition and time perception [47].
In this context, the polymorphism of the repeats in tandem SLC6A3 3'-UTR VNTR located in the 15 exon of the $3^{\prime}$ untranslated region, contains serial repetitions of $40 \mathrm{bp}$ ranging from 3 -repeats (3R) to 13-repeats. (13R), and the 9-repeats (9R) and 10-repeats (10R) series are the most common alleles in the general population. Consistent with the dopamine transporter (DAT) functionality, carriers of a $9 \mathrm{R}$ allele exhibit lower DAT protein encoding in the prefrontal cortex when compared to their 10R homozygous homologues. Although the protein structure is not altered, it is thought that function is affected by regulating mRNA stability, transport and protein synthesis [47]. The functional alleles 10R and $9 \mathrm{R}$ alter the related phenotypes with planning and execution processes of working memory tasks, stimuli perception and increase the risk of neurological diseases [48-50] because of patients with a 9R allele exhibit less DAT activity than their homozygotes 10R. In the prefrontal cortex and caudate nucleus, and thus modulate dopamine levels in the CNS during the processing of temporal and cognitive information [51, 52].

The studies are also based on the influence of dopamine-degrading enzymes, especially the COMT gene located in 22q11, which encodes dopaminergic degradation in the synaptic cleft. The COMT gene encodes the enzyme catechol-o-methyltransferase (COMT enzyme) that catalyzes the transfer of a methyl group from S-adenosylmethionine to catecholamines [11]. The level of degradation is modified by means of the COMT Val158Met polymorphism, known to influence enzymatic activity in the prefrontal cortex, increasing the dopaminergic levels and thus deregulating the nigrostriatal circuit in the time delay of supra seconds. Carriers of the Met allele $(\mathrm{L})$ are more visualized in time-stamping studies by means of motor and cognitive tasks in patients with Parkinson's disease [18]. Carriers of the Met allele (L) have relatively low COMT enzyme activity and, presumably, have greater availability of dopamine. While the carriers of the Val allele $(\mathrm{H})$ have a relatively high activity of COMT enzyme, and less availability of dopamine $[11,53]$. The COMT Val158Met polymorphism has been associated with impairments in working memory [11], emotional problems [54], reduced attention levels [20], and associated with a risk of neurological diseases $[55,56]$. Thus, the influence on the perception of time due to these neurological disorders is presumed to act in brain areas responsible for coding processes of time intervals, and in cognitive functions embedded in the timing.

Bartholomew et al. [6] have shown the hypothesis of genetic polymorphisms influencing the time interpretation and express complex human phenotypes. The authors reported that genetic polymorphisms contribute to individual variability in neurobiological aspects at 
internal clock speed. In the study methodology, 647 healthy individuals were analyzed in production and discrimination of time intervals, however, only 148 individuals were examined based on Genome-wide association study (GWAS) to see if any genetic polymorphism is associated with a trait. GWAS typically focus on associations between SNPs and human traits for different phenotypes in timing. The authors used the DRD2/ANKK1-Taq1A, SLC6A3 3'-UTR VNTR, and COMT Val158Met, which are correlated with precision in judging of time intervals. The genotypes were chosen based on the minor allele frequency (MAF) greater than 5\%, and thus, the neurobiological data related to MAF identified common variations that may contribute to the understanding of the human behavioral phenotype in time coding.

Meck et al. [8], based on molecular influence on dopaminergic neurotransmission, the authors assessed behavioral phenotype in knockout rats for the SLC6A3 and COMT gene and under the influence of drug. The authors concluded that the circuits of the prefrontal cortex and striatum have less activation during the encoding of stimuli, which is due to changes in the neurotransmitter levels due alterations in COMT enzyme and DAT. On the basis of this, we propose that the genetic polymorphisms SLC6A3 3'-UTR VNTR and COMT Val158Met alter the internal clock speed by decreasing accuracy in judging time intervals. Thus, the neural substrates underlying the three clock stages (clock phase, memory phase, and decision) can be modulated according to the genetic polymorphisms, which is likely due to changes in dopaminergic pathways. According to this model, dopamine participates mainly in the clock phase. An increase in dopaminergic signaling accelerates the accumulation of impulses over time and modifies the coding process of accumulated information, and consequently distorts judgment time [5].

Transport, receptors and dopaminergic degradation have been shown to be critical for the time interval in humans and animals [57]. Experiments with genetically knockout mice for SLC6A3 and DRD2 have increased levels of dopamine in the prefrontal cortex and neural inputs deficient in neurotransmitter via the nigrostriatal pathway. Elevated levels of the neurotransmitter imply impairment both in the time interval and in the motivation to work for food rewards [23]. In association with these characteristics, it was shown that deficits in time accuracy appear to be mediated by deficiencies in the systems of motivation, working memory or sustained attention. In general, the overall alteration of DAT and D2 receptor expression through SLC6A3 3'-UTR VNTR and DRD2/ANKK1-TAq1A results in underestimation in timing of behavior. It is inferred that the resulting effect does not resemble the effect of clock speed induced by injections of drug dopaminergic agonists when rats are trained by peak interval (PI) [58].

\section{Influence of clock genes in the timing}

The innate preference in the morning or evening is one of the characteristics determined by the circadian rhythm phase. From this circadian synchronization, our brain as an efficient machine in the orchestration of time scales encodes physiological information and cognitive behaviors $[58,59]$. In mammals, this system is organized by a central clock located in the suprachiasmatic nucleus (SCN) of the hypothalamus, in addition to a series of peripheral oscillators present in the liver, lungs, adrenal glands, and other tissues [59-61].

The SCN regulates the biological rhythms of the organism through self-regulated transcription-translation loops of the so-called CLOCK genes in a 24-h period, with the CLOCK, ARNTL, PER (1, 2 and 3) and CRY (1 and 2) $[62,63]$. Briefly, the CLOCK/ARNTL protein complex expresses negative regulators PER1-3 and CRY1-2 proteins, since they inhibit the expression of the CLOCK/ARNTL heterodimer. The CLOCK/ARNTL heterodimer controls the genetic expression acting in the physiology of the organism and, thus, the modulation of heterodimer levels leads to the rhythmicity of various metabolic and cognitive functions [59, 64, 65].

The control of CLOCK-ARNTL heterodimer levels exhibits time-dependent fluctuations, and thus modulate the synchronization capability of shorter intervals, such as second-to-minutes [65, 66]. Agostino and Cheng [58] provided experimental evidence showing changes in dopaminergic levels in rat striatum as a function of the circadian cycle, with lower levels of dopamine during the day and a peak at night. This occurs due to regulators in the promoter region of the $S L C 6 A 3, D R D 1$ and $M A O A$ genes, demonstrating that the expression of these components is linked to cycles of luminosity and metabolic variations [58]. Rats with modulations in the dopaminergic, levels in the dorsal striatum for lack of melatonin have an impact on the stimuli perception in fixed interval tasks. In addition, the lack of melatonin has been associated with circadian clock components, focusing on the PER2 gene. The genetic expression of $P E R 2$ is involved in the circadian regulation of dopaminergic metabolism through dorsal striatum and substantia nigra pars compacta (SNpc) oscillations [58].

Therefore, it is increasingly accepted that the variations in genetic components of circadian rhythm affect the rhythmicity of the organism in timing as well as environmental changes [59, 67]. In exemplification, workers who abruptly change their work shift may present mood problems, social and work activities, as well as favor the development of deficient cognitive functions $[68,69]$. It has been shown that the PER2 gene effect on insomnia was relatively stronger than environmental factors such as high stress at work. Thus, it is suggested that the genetic susceptibility of the individual 
should be considered for the sleep problems control [70]. In the context, Song et al. [71], in a Korean population, demonstrated that in addition to the involvement of the PER2 gene, a synergistic action with other circadian genes may increase the risk of the diurnal preference toward evening [71]. Given the influence of genetic variations related to the circadian rhythm on sleep homeostasis, it is easier to understand how endogenous rhythmicity influences the interval timing, as changes in the sleep-wake cycle influence the processing of shorter time intervals. Späti et al. [66], analyzed the time perception of individuals who experienced sleep deprivation, and their findings showed that sustained wakefulness distorts the timing interval through pacemaker pulse oscillations over a 24-h period, with an exponential increase and saturation in the rate of the pacemaker with time constant of $18.2 \mathrm{~h}$.

Neural synchronism deficient in the coding of the time intervals led by circadian dysregulation was studied by means of time estimation tasks with rats under conditions of $24 \mathrm{~h}$ in the dark (D/D) or $24 \mathrm{~h}$ in the daylight $(\mathrm{L} / \mathrm{L})$, different of the normal homeostatic condition of $12 \mathrm{~h}$ light / $12 \mathrm{~h}$ dark (L/D) [72]. Agostino et al. [72] observed that the group trained in the DD condition showed higher precision, whereas in the L/L condition the rats lost temporal control. This evidence is important in view of the fact that the light is the main cue for circadian rhythm. The time perception, in addition to varying with the time of day, is strongly correlated with circadian variations in body temperature and serum melatonin levels [73]. The circadian rhythm is indicated as a regulator of the interval timing by means of modulations in the dopamine levels, which is implicated as a key neurotransmitter responsible for the pacemaker-accumulator operation [67]. In fact, the processing of timing interval involves the interaction of cortico-striatal circuits through the dopaminergic-glutamatergic pathways. With this, alteration in dopaminergic neurotransmission during the day caused by circadian dysfunctions strongly influences the timing interval. However, the changes in neurotransmitter levels were shown to be reversed by levodopa injections in rats with circadian timing disruptions. So, it is suggested that a daily increase in dopamine is required for the accurate performance of timekeeping tasks [74].

Polymorphisms in different genomic regions are not only responsible for the stable changes throughout the organism, but also have the potential to modulate neural coding for interval timing [75]. In summary, the circadian genes expression in the striatum and substantia nigra, important structures involved in temporal processing and dopaminergic neurotransmission, influence neural oscillations when L/L conditions are induced [74]. If on the one hand, circadian changes alter the expression of dopamine and consequently the timing interval, dopamine-associated polymorphisms have also been implicated in circadian changes, showing a clear synergism between two systems [76].

\section{Genetic of the GABAergic system have an impact on neurobiological aspects inbuilt in the time perception}

The $\beta 2 \mathrm{GABA}_{\mathrm{A}}$ subunit receptor is a multiple subunit chloride channel receptor that mediates the action of gamma-aminobutyric acid (GABA), a fast inhibitor of synaptic transmission in the CNS. The receptor is expressed by the GABRB2 gene, located at 9q22.1-q22.3, which plays a role in modulating synapses and maintains the excitation-inhibition balance in the brain [77]. Different genetic polymorphisms alter the expression or function of elements of GABAergic neurotransmissions, such as the SNP GABRB2 A/C type intronic polymorphism that decrease the expression of messenger RNA (mRNA) required for the synthesis of $\beta 2$ subunit. This polymorphism decreases GABA concentration at the postsynaptic level and has thus been associated with changes in memory and attention, both influencing time-interval processing $[5,78]$. It has been argued that GABRB2 A/C modulates $\beta 2$ subunit activity of the $\mathrm{GABA}_{\mathrm{A}}$ receptor in various time interval regions, specifically the visual cortex, frontal cortex, dopaminergic circuit associations and striatal-thalamic-cortical [79]. In this sense, it modifies the temporal processing of information obtained from the activity of sensory receptors, which is responsible for capturing and redirecting information to be interpreted in executive actions proposed in the classical pacemaker-accumulator model, this is consistent with the role of neural oscillations in synchronizing parts of distributed modular clocks in the brain (Fig. 1) [80-84].

Experimental evidence suggests that GABAergic fast inhibitory neurotransmission - mediated by $\mathrm{GABA}_{\mathrm{A}}$ receptor subtype - plays a key role in beta oscillations as shown by a study of the primary motor cortex of rats [85]. Furthermore, linkage and association mapping between genetic polymorphisms (microsatellite and single-nucleotide polymorphisms) shows significant dependence of beta-range oscillation phenotypes with GABAA gene location in chromosome 4 [85, 86]. More experimental evidence directly implicates GABAergic transmission in timing functions of the brain. In a psychophysics study, measuring visual interval estimation and reproduction, it was shown that the elevated levels of GABA in the visual cortex lead to the underestimation of visual intervals [77].

Kononowicz and Van Rijn [87] showed that subjective timing of millisecond intervals does not depend on changes indexed by the evoked potential known as contingent negative variation, and that the subjective experience of time is better reflected by distinct features of 


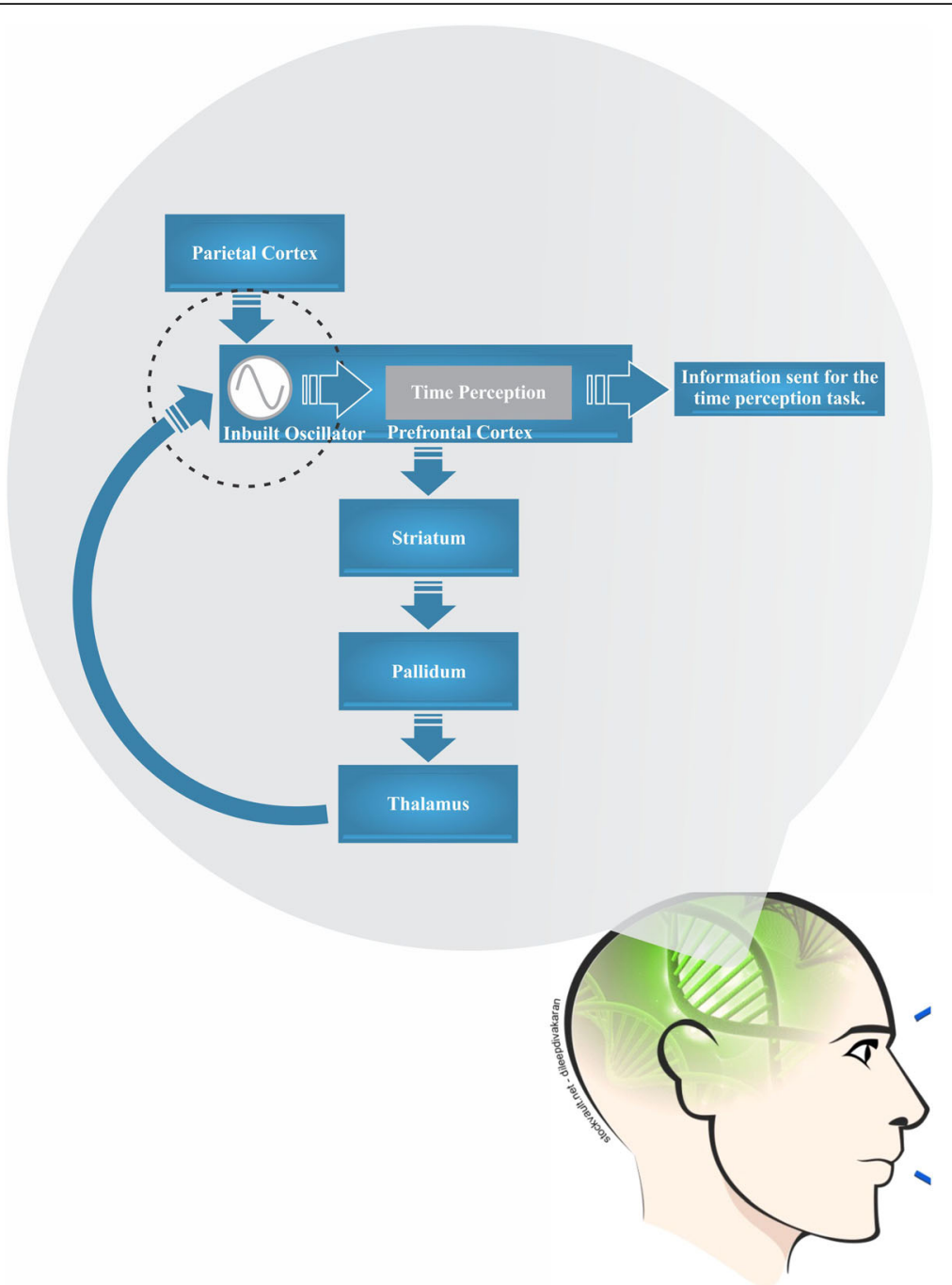

Fig. 1 Modular connection among the parietal cortex, prefrontal cortex and striatum. The proposed inbuilt modular clock in the prefrontal cortex is responsible for synchronizing the time perception. Genetic polymorphisms modulate the functions of the parietal and prefrontal cortex; reduced interference in the role of striatal oscillations in the representation of time intervals in the brain. Thus, decreases the efficiency in coding the time intervals

evoked potentials occurring after offset of comparison interval in a time estimation task [87]. In addition, the authors demonstrated that the neural responses evoked from GABAergic connections predicted the subjective perception of the comparison interval, with evoked responses more similar to the normal interval, independently of the duration presented [87, 88]. Furthermore, experimental evidences by means of computational modeling demonstrate GABAergic neurons inhibitory to the production of gamma oscillations in electroencephalography [89], as well as the GABA performance in the visual cortex for the differences in the individual phenotypes, as consequence of the decrease of the threshold of synchronization of visual stimuli $[77,87,88]$.

Van Loon et al. [89] analyzed differences in the processing of visual stimuli due to the synchronism of
GABAergic neurons, implying, therefore, that GABA acts as a mediator in the perception of visual intervals. Thus, experiments with pharmacological modeling of GABAergic agonists and antagonists in accordance with genomic analyses are suggested to elucidate the role of GABAergic system in time discrimination tasks [77, 90]. Furthermore, GABAergic activity is susceptible to the modulation of time perception and the polymorphic form GABRB2 A/C and its haplotypes have the capacity to influence the risk of neurological diseases (i.e., Parkinson's Disease, Schizophrenia, Bipolar Disorder), which affect the processing of time intervals by the brain in laboratory-controlled tasks or in the performance of everyday activities [78, 91]. In addition, the study by Oblack, Gibbs, and Blat [92] has shown that the neurobiological aspects related to the perceptual capacity of 
time in autistic subjects is deficient, which is associated with elevations of GABAergic activity in the visual cortex and auditory cortex. Moreover, these results may reveal underestimation of the time in relation to the timing of the stimuli $[89,90]$.

Another aspect of the GABA as an inhibitor of synaptic transmission in the CNS, is demonstrated through postsynaptic polarization, and decrease of intracellular $\mathrm{Ca}_{2+}$ levels in the medium spiny neurons. This occurs by means of GABAergic loops that are also important for interval timing mechanisms, among which are the glutamic acid decarboxylase (GAD), an enzyme that converts glutamate to GABA. The GAD1 gene encodes the GAD67 in both the cell body and nerve terminals. GAD65, on the other hand, is encoded by the GAD2 gene and is restricted to the nerve terminals [78, 93]. It can be hypothesized that reduced inhibitory transmission in the brain may play a role in timing based on the level these two isoforms, GAD65 and GAD67. Reduced synthesis of GABA due to inhibition or decreased levels of GAD may result in neural inputs deficits inbuilt in neurobiological aspects in timing, such as stimulus perception, decision-making and memory. Clearly, a dysregulation of glutamate and GABA metabolism in the brain may contribute to neurological diseases that affect the time judgment (for example, Anxiety disorders and Depression) [77, 93].

Few studies have evaluated the hypothesis of the genetic interaction of GABRB2 $\mathrm{A} / \mathrm{C}$ on the interindividual variability of behavioral phenotypes related to a timing error in healthy individuals or in patients with some neurological disease. However, few state-of-the-art demonstrates studies studied electrophysiological measures of neural firing in monkeys the GABAergic performance in the coding and timing of stimuli [94-96]. Interestingly, they showed that the perceived duration is a consequence of the magnitude of the neuronal response at visual time-intervals in GABAergic circuits. The findings suggest a link between electrophysiological results due to inhibition of the specific sensory excitatory activity of the optical pathways of visual stimulation $[89,97,98]$. It may be that the prediction of the error as a function of the perceptual capacity is determined by local calcium limitations in the activation of the GABA receptors in the visual cortex, which affects the excitation-inhibition equilibrium [99].

\section{Limitations of existing research}

Some factors, such as sensory modality, intensity, size, complexity, familiarity are not standardized in the various studies of the time perception, making it impossible to completely determine the association with genetic polymorphisms in the neural inputs during time coding. Limitations involved on population size and further studies with larger samples are needed to determine whether such genetic polymorphisms alone may or may not help explain the interindividual differences in timing. A limitation of this study, are few works that relate genetics on time perception, in particular, the variation referring to the neurotransmitter GABA. The presented studies suggest an applicability of the GABRB2 variants in the timing since it modifies in the inbuilt oscillator in executive functions essential in the judgment of the time.

\section{Conclusion}

The study of genetic polymorphisms is not only relevant to health, but also to various behavioral phenotypes that alter the temporal judgment. Thus, more studies are needed to substantiate the genotypic contributions on performance in temporal activities, by understanding the neurobiological mechanisms at the molecular and biochemical level behind timing synchronism. In summary, levels of neurotransmitters such as serotonin and dopamine are regulated by SLC6A4, 5HTR2A, DRD2/ANKK1, SLC6A3, and COMT gene that modulate the chemistry of the neural bases in the prefrontal circuits [100], associated with studies of cognition and working memory [101], learning and repetitive motor tasks in relation to a visual stimulus [102]. Regarding the $C L O C K$ genes, corticosteroid changes due to alterations in PER2 expression promoted impacts in the time interval, as it acts on the dopaminergic metabolism due to the influence of circadian variations induced by changes in the light / dark cycle.

Furthermore, few studies have analyzed the GABRB2 A/ $C$ polymorphism in time perception tasks, and our hypothesis of acting on time intervals is supported by changes in the processing of perceptual process information in the visual cortex, suggested by changes in neural oscillations. In circadian pacemakers, for example, the SCN, due to limitations in the activation of GABA receptors in the visual cortex, affects the excitation-inhibition balance in the visual stimuli perception. Thus, genetic and cognitive information provide the means that direct the mechanisms underlying the perceptual behavior of time in humans.

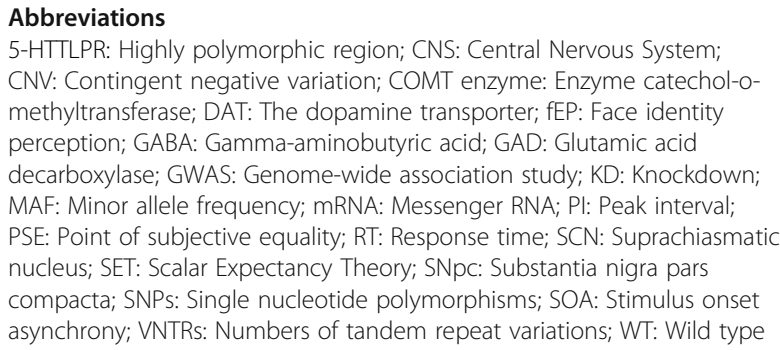

VM, TO, JB, GRP, DG, PR, BV and ST designed the study concept. Studies considered eligible for inclusion were read in full and their suitability for inclusion was determined independently by six reviewers (VM, $A G, V L, F M$, $K R$, and $V C$ ). $(A, M O, V H B$, and $J B$ read and finalized the manuscript. All authors read and approved the final manuscript. 


\section{Authors' information}

VM, TO, AG and VL are researchers of the Neuro-innovation Technology \& Brain Mapping Laboratory, Federal University of Piauí, Parnaíba, Brazil, and Genetics and Molecular Biology Laboratory, Federal University of Piauí, Parnaíba, Brazil.

$\mathrm{JB}, \mathrm{KR}, \mathrm{FM}, \mathrm{VC}$, and $\mathrm{CA}$ are researchers of the Neuro-innovation Technology \& Brain Mapping Laboratory, Federal University of Piauí, Parnaíba, Brazil. GRP is a professor and mentor in the Master and PhD programs at Federal University of Piauí. He is a head of the Genetics and Molecular Biology Laboratory.

BV and PR are professors at the Federal University of Rio de Janeiro, and Brain Mapping and Sensory Motor Integration Laboratory, Institute of Psychiatry of Federal University of Rio de Janeiro, Brazil.

$\mathrm{MO}$ is professor of Master's Program in Local Development and Health Sciences Applied Program on University Center Augusto Motta - UNISUAM, Rio de Janeiro, Brazil.

DG is an adjunct professor of Biology at Camden County College,

Blackwood, New Jersey, USA.

VHB is professor at the Federal University of Piauí. Mentor in the Master program at Federal University of Piauí. He is a head of the Brain Mapping and Functionality Laboratory.

ST is professor at the Federal University of Piauí. Mentor in the Master and PhD. programs at Federal University of Piauí. He is a head of the Neuroinnovation Technology \& Brain Mapping Laboratory.

\section{Ethics approval and consent to participate}

Not applicable.

\section{Consent for publication}

Not applicable.

\section{Competing interests}

The authors declare that they have no competing interests.

\section{Publisher's Note}

Springer Nature remains neutral with regard to jurisdictional claims in published maps and institutional affiliations.

\begin{abstract}
Author details
${ }^{1}$ Neuro-innovation Technology \& Brain Mapping Laboratory, Federal University of Piauí, Av. São Sebastião n² 2819 - Nossa Sra. de Fátima Parnaíba, PI CEP 64202-020, Brazil. ${ }^{2}$ Genetics and Molecular Biology Laboratory, Federal University of Piauí, Parnaíba, Brazil. ${ }^{3}$ The Northeast Biotechnology Network (RENORBIO), Federal University of Piauí, Teresina, Brazil. ${ }^{4}$ Brain Mapping and Sensory Motor Integration Laboratory, Federal University of Rio de Janeiro, Rio de Janeiro, Brazil. ${ }^{5}$ Master's Program in Local Development Program, University Center Augusto Motta - UNISUAM, Rio de Janeiro, Brazil and Health Sciences Applied - Vassouras University, Rio de Janeiro, Brazil. 'Brain Mapping and Functionality Laboratory, Federal University of Piauí, Parnaíba, Brazil. ${ }^{7}$ Department of Biology, Camden County College, Blackwood, NJ, USA.
\end{abstract}

Received: 9 June 2018 Accepted: 31 July 2018

Published online: 07 August 2018

\section{References}

1. Balci F, Ludvig EA, Abner R, Zhuang X, Poon P, Brunner D. Motivational effects on interval timing in dopamine transporter (DAT) knockdown mice. Brain Res. 2010;1325(14):89-99.

2. Herai T, Mogi K. Perception of temporal duration affected by automatic and controlled movements. Conscious Cogn. 2014;29:23-35.

3. Merchant $\mathrm{H}$, Harrington DL, Meck WH. Neural basis of the perception and estimation of time. Annu Rev Neurosci. 2013;36:313-36.

4. Zhang L, Ptáček $L$, Fu YH. Diversity of human clock genotypes and consequences. Prog Mol Biol Transl Sci. 2013;119:51-81.

5. Matthews WJ, Meck WH. Time perception: the bad news and the good. Wiley Interdiscip Rev Cogn Sci. 2014;5(4):429-46.

6. Bartholomew AJ, Meck WH, Cirulli ET. Analysis of genetic and non-genetic factors influencing timing and time perception. PLoS One. 2015;10(12): e0143873.
7. Balci F, Wiener M, Cavdaroğlu B, Branch CH. Epistasis effects of dopamine genes on interval timing and reward magnitude in humans. Neuropsychologia. 2013;51(2):293-308.

8. Meck WH, Cheng RK, MacDonald CJ, Gainetdinov RR, Caron MG, Cevik MÖ. Gene-dose dependent effects of methamphetamine on interval timing in dopamine-transporter knockout mice. Neuropharmacology. 2012;62(3): $1221-9$.

9. Zilles D, Meyer J, Schneider-Axmann T, Ekawardhani S, Gruber E, Falkai P, Gruber O. Genetic polymorphisms of 5-HTT and DAT but not COMT differentially affect verbal and visuospatial working memory functioning. Eur Arch Psychiatry Clin Neurosci. 2012;262(8):667-76.

10. Fallgatter AJ, Herrmann MJ, Roemmler J, Ehlis AC, Wagener A, Heidrich A, Ortega G, Zeng Y, Lesch KP. Allelic variation of serotonin transporter function modulates the brain electrical response for error processing. Neuropsychopharmacology. 2004;29(8):1506-11.

11. Green AE, Munafò MR, DeYoung CG, Fossella JA, Fan J, Gray JR. Using genetic data in cognitive neuroscience: from growing pains to genuine insights. Nat Rev Neurosci. 2008;9(9):710-20.

12. Cirulli ET, Kasperaviciūte D, Attix DK, Need AC, Ge D, Gibson G, Goldstein DB. Common genetic variation and performance on standardized cognitive tests. Eur J Hum Genet. 2010;18(7):815-20.

13. Sysoeva OV, Tonevitsky AG, Wackermann J. Genetic determinants of time perception mediated by the serotonergic system. PLoS One. 2010;5(9): e12650.

14. Rammsayer TH. Effects of body core temperature and brain dopamine activity on timing processes in humans. Biol Psychol. 1997;46(2):169-92.

15. Teixeira S, Machado S, Paes F, Velasques B, Silva JG, Sanfim AL, Minc D, Anghinah R, Menegaldo LL, Salama M, Cagy M, Nardi AE, Pöppel E, Bao Y, Szelag E, Ribeiro P, Arias-Carrión O. Time perception distortion in neuropsychiatric and neurological disorders. CNS Neurol Disord Drug Targets. 2013;12:567-82.

16. Allman MJ, Teki S, Griffiths TD, Meck WH. Properties of the internal clock: first-and second-order principles of subjective time. Annu Rev Psychol. 2014; 65:743-71.

17. Fontes R, Ribeiro J, Gupta DS, Machado D, Lopes-Júnior F, Magalhães F, Bastos VH, Rocha K, Marinho V, Lima G, Velasques B, Ribeiro P, Orsini M, Pessoa B, Leite MA, Teixeira S. Time perception mechanisms at central nervous system. Neurol Int. 2016;8(1):5939.

18. Jones CRG, Jahanshahi M. Dopamine modulates Striato-frontal functioning during temporal processing. Front Integr Neurosci. 2011;5:70.

19. Bender S, Rellum T, Freitag C, Resch F, Rietschel M, Treutlein J, JennenSteinmetz C, Brandeis D, Banaschewski T, Laucht M. Time-resolved influences of functional DAT1 and COMT variants on visual perception and post-processing. PLoS One. 2012;7(7):e41552.

20. Maksimov M, Vaht M, Murd C, Harro J, Bachmann T. Brain dopaminergic system related genetic variability interacts with target/mask timing in metacontrast masking. Neuropsychologia. 2015;71:112-8.

21. Wiener M, Lohoff FW, Coslett HB. Double dissociation of dopamine genes and timing in humans. J Cogn Neurosci. 2011;23:2811-21.

22. Wiener M, Lee YS, Lohoff FW, Coslett HB. Individual differences in the morphometry and activation of time perception networks are influenced by dopamine genotype. Neuroimage. 2014;89:10-22.

23. Drew MR, Simpson EH, Kellendonk C, Herzberg WG, Lipatova O, Fairhurst S, Kandel ER, Malapani C, Balsam PD. Transient overexpression of striatal D2 receptors impairs operant motivation and interval timing. J Neurosci. 2007; 27:7731-9.

24. Hildebrandt A, Kiy A, Reuter M, Sommer W, Wilhelm O. Face and emotion expression processing and the serotonin transporter polymorphism 5HTTLPR/rs22531. Genes Brain Behav. 2016;15(5):453-64.

25. Price JS, Strong J, Eliassen J, McQueeny T, Miller M, Padula CB, Shear P, Lisdahl K. Serotonin transporter gene moderates associations between mood, memory, and hippocampal volume. Behav Brain Res. 2013;242: $158-65$.

26. Schürks M, Frahnow A, Diener HC, Kurth T, Rosskopf D, Grabe HJ. Bi-allelic and tri-allelic 5-HTTLPR polymorphisms and triptan non-response in a cluster headache. J Headache Pain. 2014;21(15):46.

27. Beevers CG, Gibb BE, McGeary JE, Miller IW. Serotonin transporter genetic variation and biased attention for emotional word stimuli among psychiatric inpatients. J Abnorm Psychol. 2007;116(1):208-12.

28. Heinz A, Braus DF, Smolka MN, Wrase J, Puls I, Hermann D, Klein S, Grüsser SM, Flor H, Schumann G, Mann K, Büchel C. Amygdala prefrontal coupling 
depends on a genetic variation of the serotonin transporter. Nat Neurosci. 2005;8:20-1

29. Anderson DE, Bell TA, Awh E. Polymorphisms in the 5-HTTLPR gene mediate storage capacity of visual working memory. J Cogn Neurosci. 2012; 24(5):1069-76

30. Crişan LG, Pana $S$, Vulturar R, Heilman RM, Szekely R, Druğa B, Dragoş N, Miu AC. Genetic contributions of the serotonin transporter to social learning of fear and economic decision making. Soc Cogn Affect Neurosci. 2009;4(4):399-408.

31. Lochner $C$, Hemmings $S$, Seedat $S$, Kinnear C, Schoeman R, Annerbrink $K$, Olsson M, Eriksson E, Moolman-Smook J, Allgulander C, Stein DJ. Genetics and personality traits in patients with social anxiety disorder: a case-control study in South Africa. Eur Neuropsychopharmacol. 2007;17(5):321-7.

32. Sysoeva OV, Maluchenko NV, Timofeeva MA, Portnova GV, Kulikova MA, Tonevitsky AG, Ivanitsky AM. Aggression and 5HTT polymorphism in females: a study of synchronized swimming and control groups. Int J Psychophysiol. 2009;72(2):173-8.

33. Seripa D, Pilotto A, Paroni G, Fontana A, D'Onofrio G, Gravina C, Urbano M, Cascavilla L, Paris F, Panza F, Padovani A, Pilotto A. Role of the serotonin transporter gene locus in the response to SSRI treatment of major depressive disorder in late life. J Psychopharmacol. 2015;29(5):623-33.

34. Nomura M, Kaneko M, Okuma Y, Nomura J, Kusumi I, Koyama T, Nomura Y. Involvement of serotonin transporter gene polymorphisms (5-HTT) in impulsive behavior in the Japanese population. PLoS One. 2015;10(3):e0119743.

35. Althaus M, Groen Y, Wijers AA, Mulder LJ, Minderaa RB, Kema IP, Dijck JD, Hartman CA, Hoekstra PJ. Differential effects of 5-HTTLPR and DRD2/ANKK1 polymorphisms on electrocortical measures of error and feedback processing in children. Clin Neurophysiol. 2009;120:93-107.

36. Burt SA, Mikolajewski AJ. Preliminary evidence that specific candidate genes are associated with adolescent-onset antisocial behavior. Aggress Behav. 2008;34(4):437-45.

37. Bekinschtein P, Renner MC, Gonzalez MC, Weisstaub N. Role of medial prefrontal cortex serotonin $2 \mathrm{~A}$ receptors in the control of retrieval of recognition memory in rats. J Neurosci. 2013;33(40):15716-25.

38. Polesskaya OO, Sokolov BP. Differential expression of the "C" and "T" alleles of the 5 -HT2A receptor gene in the temporal cortex of normal individuals and schizophrenics. J Neurosci Res. 2002;67(6):812-22.

39. Chun MM. Visual working memory as visual attention sustained over time. Neuropsychologia. 2011;49:1407-9.

40. Moreau AW, Amar M, Le Roux N, Morel N, Fossier P. Serotoninergic finetuning of the excitation-inhibition balance in rat visual cortical networks. Cereb Cortex. 2010;20(2):456-67.

41. Goldman N, Glei DA, Lin YH, Weinstein M. The serotonin transporter polymorphism (5-HTTLPR): allelic variation and links with depressive symptoms. Depress Anxiety. 2010;27(3):260-9.

42. Kometer M, Schmidt A, Jäncke L, Vollenweider FX. Activation of serotonin $2 A$ receptors underlies the psilocybin-induced effects on a oscillations, N170 visualevoked potentials, and visual hallucinations. J Neurosci. 2013;33(25):10544-51.

43. Addyman C, Rocha S, Mareschal D. Mapping the origins of time: scalar errors in infant time estimation. Dev Psychol. 2014;30:a0037108.

44. Drew MR, Fairhurst S, Malapani C, Horvitz JC, Balsam PD. Effects of dopamine antagonists on the timing of two intervals. Pharmacol Biochem Behav. 2003;75(1):9-15

45. Richter A, Richter S, Barman A, Soch J, Klein M, Assmann A, Libeau C, Behnisch G, Wüstenberg T, Seidenbecher Cl, Schott BH. Motivational salience and genetic variability of dopamine D2 receptor expression interact in the modulation of interference processing. Front Hum Neurosci. 2013;5(7):250.

46. Pan YQ, Qiao L, Xue XD, Fu JH. Association between ANKK1 (rs1800497) polymorphism of DRD2 gene and attention deficit hyperactivity disorder: a meta-analysis. Neurosci Lett. 2015;590(17):101-5.

47. Shih MC, Hoexter MQ, Andrade LA, Bressan RA. Parkinson's disease and dopamine transporter neuroimaging: a critical review. Sao Paulo Med J. 2006;124(3):168-75.

48. Greenwood TA, Badner JA, Byerley W, Keck PE, McElroy SL, Remick RA, Dessa Sadovnick A, Kelsoe JR. Heritability and linkage analysis of personality in bipolar disorder. J Affect Disord. 2013;151(2):748-55.

49. Fehér Á, Juhász A, Pákáski M, Kálmán J, Janka Z. Association between the 9 repeat allele of the dopamine transporter 40bp variable tandem repeat polymorphism and Alzheimer's disease. Psychiatry Res. 2014;220(1-2):730-1.

50. Maitra S, Sarkar K, Ghosh P, Karmakar A, Bhattacharjee A, Sinha S, Mukhopadhyay K. Potential contribution of dopaminergic gene variants in
ADHD core traits and co-morbidity: a study on eastern Indian probands. Cell Mol Neurobiol. 2014;34(4):549-64.

51. Faraone SV, Spencer TJ, Madras BK, Zhang-James Y, Biederman J. Functional effects of dopamine transporter gene genotypes on in vivo dopamine transporter functioning: a meta-analysis. Mol Psychiatry. 2014;19:880-9.

52. Franke B, Hoogman M, Arias Vasquez A, Heister JG, Savelkoul PJ, Naber M, Scheffer H, Kiemeney LA, Kan CC, Kooij JJ, Buitelaar JK. Association of the dopamine transporter (SLC6A3/DAT1) gene 9-6 haplotype with adult ADHD. Am J Med Genet B Neuropsychiatr Genet. 2008;147B(8):1576-9.

53. Kanai $R$, Lloyd $H$, Bueti $D$, Walsh V. Modality-independent role of the primary auditory cortex in time estimation. Exp Brain Res. 2011;209(3):465-71.

54. Barzman D, Geise C, Lin P. Review of the genetic basis of emotion dysregulation in children and adolescents. World J Psychiatry. 2015;5(1):112-7.

55. Liu L, Cheng J, Su Y, Ji N, Gao Q, Li H, Yang L, Sun L, Qian Q, Wang Y. Deficiency of Sustained Attention in ADHD and Its Potential Genetic Contributor MAOA. J Atten Disord. 2018;22(9):878-85.

56. Wang LJ, Lee SY, Chen SL, Chang YH, Chen PS, Huang SY, Tzeng NS, Chen KC, Lee IH, Wang TY, Yang YK, Lu RB. A potential interaction between COMT and MTHFR genetic variants in Han Chinese patients with bipolar II disorder. Sci Rep. 2015;5(6):8813.

57. Rammsayer TH. On dopaminergic modulation of temporal information processing. Biol Psychol. 1993;36:209-22.

58. Agostino PV, Cheng RK. Contributions of dopaminergic signaling to timing accuracy and precision. Current Opinion in Behavioral Sciences. 2016;8:153-60.

59. Valenzuela FJ, Vera J, Venegas C, Muñoz S, Oyarce S, Muñoz K, Lagunas C. Evidences of polymorphism associated with circadian system and risk of pathologies: a review of the literature. Int J Endocrinol. 2016;2016:2746909.

60. Hu Y, Shmygelska A, Tran D, Eriksson N, Tung JY, Hinds DA. GWAS of 89,283 individuals identifies genetic variants associated with self-reporting of being a morning person. Nat Commun. 2016;7:10448.

61. Karthikeyan R, Marimuthu G, Ramasubramanian C, Arunachal G, BaHammam AS, Spence DW, Cardinali DP, Brown GM, Pandi-Perumal SR. Association of Per3 length polymorphism with bipolar I disorder and schizophrenia. Neuropsychiatr Dis Treat. 2014;10:2325-30.

62. Ofte HK, Tronvik E, Alstadhaug KB. Lack of association between a cluster headache and PER3 clock gene polymorphism. J Headache Pain. 2015;17:18.

63. Ozburn AR, Purohit K, Parekh PK, Kaplan GN, Falcon E, Mukherjee S, Cates HM, McClung CA. Functional implications of the CLOCK $3111 \mathrm{~T} / \mathrm{C}$ singlenucleotide polymorphism. Front Psychiatry. 2016;7:67.

64. Karatsoreos IN. Links between Circadian Rhythms and Psychiatric Disease. Front Behav Neurosci. 2014;8:162.

65. Agostino PV, Golombek DA, Meck WH. Unwinding the molecular basis of interval and circadian timing. Front Integr Neurosci. 2011;5:64.

66. Späti J, Aritake S, Meyer AH, Kitamura S, Hida A, Higuchi S, Moriguchi Y, Mishima K. Modeling circadian and sleep-homeostatic effects on short-term interval timing. Front Integr Neurosci. 2015;9:15.

67. Golombek DA, Bussi IL, Agostino PV. Minutes, days and years: molecular interactions among different scales of biological timing. Philos Trans R Soc Lond Ser B Biol Sci. 2014;369(1637):20120465.

68. Wilsmore BR, Grunstein RR, Fransen M, Woodward M, Norton R, Ameratunga S. Sleep habits, insomnia, and daytime sleepiness in a large and healthy community-based sample of new Zealanders. J Clin Sleep Med. 2013;9(6):559-66.

69. Wang $\mathrm{H}$, Chen HOS. Association of clock gene polymorphism with insulin resistance in hypertension: a case-control study. J Hypertens. 2016;34:33-9.

70. Li J, Huang C, Lan Y, Wang Y. A cross-sectional study on the relationships among the polymorphism of period2 gene, work stress, and insomnia. Sleep Breath. 2015;19(4):1399-406.

71. Song HM, Cho CH, Lee HJ, Moon JH, Kang SG, Yoon HK, Park YM, Kim L. Association of CLOCK, ARNTL, PER2, and GNB3 polymorphisms with diurnal preference in a Korean population. Chronobiol Int. 2016;33(10):1455-63.

72. Agostino PV, do Nascimento M, Bussi IL, Eguía MC, Golombek DA. Circadian modulation of interval timing in mice. Brain Res. 2011;1370:154-63.

73. Kuriyama K, Uchiyama M, Suzuki H, Tagaya H, Ozaki A, Aritake S, Shibui K, Xin T, Lan L, Kamei Y, Takahashi K. Diurnal fluctuation of time perception under 30-h sustained wakefulness. Neurosci Res. 2005;53(2):123-8.

74. Bussi IL, Levín G, Golombek DA, Agostino PV. Involvement of dopamine signaling in the circadian modulation of interval timing. Eur J Neurosci. 2014:40(1):2299-310.

75. Tucci V, Buhusi CV, Gallistel R, Meck WH. Towards an integrated understanding of the biology of timing. Philos Trans R Soc Lond Ser B Biol Sci. 2014;369(1637):20120470. 
76. Valomon A, Holst SC, Bachmann V, Viola AU, Schmidt C, Zürcher J, Berger W, Cajochen C, Landolt HP. Genetic polymorphisms of DAT1 and COMT differentially associate with actigraphy-derived sleep-wake cycles in young adults. Chronobiol Int. 2014;31(5):705-14.

77. Terhune DB, Russo S, Near J, Stagg CJ, Cohen KR. GABA predicts time perception. J Neurosci. 2014;34(12):4364-70.

78. Tsang SY, Zhong S, Mei L, Chen J, Ng SK, Pun FW, Zhao C, Jing B, Chark R, Guo J, Tan Y, Li L, Wang C, Chew SH, Xue H. Social cognitive role of schizophrenia candidate gene GABRB2. PLoS One. 2013;8(4):e62322.

79. DeWoskin D, Myung J, Belle MD, Piggins HD, Takumi T, Forger DB. Distinct roles for GABA across multiple timescales in mammalian circadian timekeeping. Proc Natl Acad Sci U S A. 2015;112(29):E3911-9.

80. Block RA, Grondin S. Timing and time perception: a selective review and commentary on recent reviews. Front Psychol. 2014;5:648.

81. Gupta DS. Processing of sub- and supra-second intervals in the primate brain results from the calibration of neuronal oscillators via sensory, motor, and feedback processes. Front Psychol. 2014;5:816.

82. Gupta DS, Chen L. 2016. Brain oscillations in perception, timing and action. Current Opinion in Behavioral Sciences. 2016;8:161-6.

83. Kononowicz TW, Van Wassenhove V. In search of oscillatory traces of the internal clock. Front Psychol. 2016;7:224.

84. Chen $Y$, Huang X. Modulation of alpha and Beta oscillations during an nback task with varying temporal memory load. Front Psychol. 2015;6:2031.

85. Lacey MG, Gooding-Williams G, Prokic EJ, Yamawaki N, Hall SD, Stanford IM, Woodhall GL. Spike firing and IPSPs in layer V pyramidal neurons during beta oscillations in rat primary motor cortex (M1) in vitro. PLoS One. 2014;9: e85109.

86. Kraja AT, Borecki IB, Province MA. Microsatellite linkage analysis, singlenucleotide polymorphisms, and haplotype associations with ECB21 in the COGA data. BMC Genet. 2005;6(1):S94

87. Kononowicz TW, van Rijn H. Decoupling interval timing and climbing neural activity: a dissociation between CNV and N1P2 amplitudes. J Neurosci. 2014; 34:2931-9.

88. Buzsáki G, Wang XJ. Mechanisms of gamma oscillations. Annu Rev Neurosci. 2012;35:203-25.

89. van Loon AM, Scholte HS, van Gaal S, van der Hoort BJ, Lamme VA. GABAA agonist reduces visual awareness: a masking-EEG experiment. J Cogn Neurosci. 2012;24:965-74.

90. Giersch A, Herzog MH. Lorazepam strongly prolongs visual information processing. Neuropsychopharmacology. 2004;29:1386-94.

91. Heaney CF, Kinney JW. Role of GABA(B) receptors in learning and memory and neurological disorders. Neurosci Biobehav Rev. 2016;63:1-28.

92. Oblak A, Gibbs TT, Blatt GJ. Reduced serotonin receptor subtypes in a limbic and a neocortical region in autism. Autism Res. 2013;6(6):571-83.

93. Unschuld PG, Ising M, Specht M, Erhardt A, Ripke S, Heck A, Kloiber S, Straub V, Brueckl T, Müller-Myhsok B, Holsboer F, Binder EB. Polymorphisms in the GAD2 gene-region are associated with susceptibility for unipolar depression and with a risk factor for anxiety disorders. Am J Med Genet B Neuropsychiatr Genet. 2009;150B(8): 1100-9.

94. Sadeghi NG, Pariyadath V, Apte S, Eagleman DM, Cook EP. Neural correlates of subsecond time distortion in the middle temporal area of visual cortex. J Cogn Neurosci. 2011;23:3829-40.

95. Mayo JP, Sommer MA. Neuronal correlates of visual time perception at brief timescales. Proc Natl Acad Sci U.S.A. 2013;110:1506-11.

96. Eagleman DM, Pariyadath V. Is subjective duration a signature of coding efficiency? Philos Trans R Soc B. 2009;364:1841-51.

97. Watson TD, Petrakis IL, Edgecombe J, Perrino A, Krystal JH, Mathalon DH. Modulation of the cortical processing of novel and target stimuli by drugs affecting glutamate and GABA neurotransmission. Int J Neuropsychopharmacol. 2009;12:357-70.

98. Muthukumaraswamy SD, Edden RA, Jones DK, Swettenham JB, Singh KD. Resting GABA concentration predicts peak gamma frequency and fMRI amplitude in response to visual stimulation. Proc Natl Acad Sci U.S.A. 2009; 106:8356-61.

99. Yizhar O, Fenno LE, Prigge M, Schneider F, Davidson TJ, O'Shea DJ, Sohal VS, Goshen I, Finkelstein J, Paz JT, Stehfest K, Fudim R, Ramakrishnan C, Huguenard JR, Hegemann P, Deisseroth K. Neocortical excitation/inhibition balance in information processing and social dysfunction. Nature. 2011;477: $171-8$.
100. Kondo HM, Kitagawa N, Kitamura MS, Koizumi A, Nomura M, Kashino M Separability and commonality of auditory and visual bistable perception Cereb Cortex. 2012;22(8):1915-22.

101. Berryhill ME, Jones KT. tDCS selectively improves working memory in older adults with more education. Neurosci Lett. 2012;521:148-51.

102. Stelzel C, Basten U, Montag C, Reuter M, Fiebach CJ. Frontostriatal involvement in task switching depends on genetic differences in D2 receptor density. J Neurosci. 2010;30(42):14205-12.

\section{Ready to submit your research? Choose BMC and benefit from:}

- fast, convenient online submission

- thorough peer review by experienced researchers in your field

- rapid publication on acceptance

- support for research data, including large and complex data types

- gold Open Access which fosters wider collaboration and increased citations

- maximum visibility for your research: over $100 \mathrm{M}$ website views per year

At BMC, research is always in progress.

Learn more biomedcentral.com/submissions 